\title{
Gender perspectives on views and preferences of older people on exercise to prevent falls: a systematic mixed studies review
}

Marlene Sandlund ${ }^{1 *}$ (D, Dawn A. Skelton ${ }^{2}$, Petra Pohl ${ }^{3}$, Christina Ahlgren ${ }^{1}$, Anita Melander-Wikman ${ }^{4}$ and Lillemor Lundin-Olsson ${ }^{1}$

\begin{abstract}
Background: To offer fall prevention exercise programs that attract older people of both sexes there is a need to understand both women's and men's views and preferences regarding these programs. This paper aims to systematically review the literature to explore any underlying gender perspectives or gender interpretations on older people's views or preferences regarding uptake and adherence to exercise to prevent falls.

Methods: A review of the literature was carried out using a convergent qualitative design based on systematic searches of seven electronic databases (PubMed, CINAHL, Amed, PsycINFO, Scopus, PEDro, and OTseeker). Two investigators identified eligible studies. Each included article was read by at least two authors independently to extract data into tables. Views and preferences reported were coded and summarized in themes of facilitators and barriers using a thematic analysis approach.

Results: Nine hundred and nine unique studies were identified. Twenty five studies met the criteria for inclusion. Only five of these contained a gender analysis of men's and women's views on fall prevention exercises. The results suggests that both women and men see women as more receptive to and in more need of fall prevention messages. The synthesis from all 25 studies identified six themes illustrating facilitators and six themes describing barriers for older people either starting or adhering to fall prevention exercise. The facilitators were: support from professionals or family; social interaction; perceived benefits; a supportive exercise context; feelings of commitment; and having fun. Barriers were: practical issues; concerns about exercise; unawareness; reduced health status; lack of support; and lack of interest. Considerably more women than men were included in the studies.

Conclusion: Although there is plenty of information on the facilitators and barriers to falls prevention exercise in older people, there is a distinct lack of studies investigating differences or similarities in older women's and men's views regarding fall prevention exercise. In order to ensure that fall prevention exercise is appealing to both sexes and that the inclusion of both men and women are encouraged, more research is needed to find out whether gender differences exists and whether practitioners need to offer a range of opportunities and support strategies to attract both women and men to falls prevention exercise.
\end{abstract}

Keywords: Accidental falls, Adherence, Aged, Exercise, Gender identity

\footnotetext{
*Correspondence: marlene.sandlund@umu.se

'Department of Community Medicine and Rehabilitation, Physiotherapy,

Umeå University, Umeå, Sweden

Full list of author information is available at the end of the article
} 


\section{Background}

Falls present the most common cause of injury in old age. At least one third of people aged 65-years and above fall every year, half of them more than once [1], and the incidence increases with advancing age [2]. Women are more prone to falling compared to men and sustain more fall related injuries [3]. The annual rates of nonfatal injuries due to falls for women have been reported to be $48.4 \%$ higher than the rates for men [4]. However, a recent study has shown that when the values for comorbidities, lean and fat body mass, and balance were similar between men and women, men actually demonstrated a higher probability of falling [5]. Indeed, men in all age groups are more likely than women to suffer from a fatal fall injury [4]. It is, therefore, important to consider men in fall prevention research and interventions.

According to recent systematic reviews and metaanalyses on interventions to reduce falls, exercise programs that focus on balance combined with muscle strength in the lower limbs are effective interventions to address risk and rate of falling [6, 7]. Exercise programs delivered at home with support from health professionals are cost effective, at least in adults 80 years and older, and cost neutral in those younger [8]. However, both group and home based fall prevention exercise programs are effective as long as they are performed for an effective length of time, regularly enough, and include adequate strength and balance progression [7, 9].

Despite consistent evidence that strength and balance training is effective in reducing falls and fall related injuries across a range of ages and settings, participant uptake is often poor. In a recent systematic review of older people's participation in and engagement with fall prevention interventions in community settings, only $64.2 \%$ accepted the invitation to join the exercise intervention and $19.4 \%$ then dropped out of the intervention when they learned what the intervention entailed. However, once they started the intervention there was a $90 \%$ retention to the end of the intervention [10]. Average adherence to group based exercise programs have been estimated to around 75\% [11], and for home based long term training, adherence rates lower than 50\% have been reported [12]. Previous reviews investigating views and preferences of older people for general fall prevention programs have found that 'autonomy supportive' programs, perceived as relevant and life-enhancing, facilitated participation. Such programs included education, involvement in decision-making, individually tailored interventions and social support $[13,14]$.

Research has tended to focus on women in fall prevention interventions. Between 70 and $77 \%$ of participants in reviews of intervention studies were women $[6,9]$. Men are less likely than women to report falls, seek medical care, and/or discuss falls and fall prevention with a healthcare provider [15]. In order to offer fall prevention exercise programs that attract older people of both sexes there is a need to understand both women's and men's views and preferences regarding these programs. With the exception of walking, which is the most common type of leisure time physical activity for both women and men in most cultures, women tend to prefer different types of physical activity than men [16]. Different exercise programs may have different 'meanings' to men and women and the way in which we market these opportunities or how they are run may have differing effects in terms of uptake and adherence for them. Therefore, careful analysis of womens' and mens' views and preferences to the delivery of falls prevention exercise is crucial.

No previous reviews have explicitly considered similarities or differences between men and women in their views or preferences. Therefore, the aim of this study was to review the literature and explore underlying gender perspectives within older people's views or preferences regarding uptake and adherence to exercise to prevent falls.

\section{Method}

Although this review was interested in gender perspectives, a pilot scoping review prior to this study suggested very little literature with gender views or preferences specifically. Therefore it was decided not to apply an inclusion criteria based on gender, but instead review all current literature on the topic and extract any gender information reported within the wider literature for this review. The research question was "What are the views and preferences of older adults in exercise to prevent falls and are there any differences between women and men?"

\section{Criteria for considering studies for this review Types of studies}

Both quantitative, qualitative and mixed methods articles were included in this review to ensure this review was as inclusive as possible. The key feature of this review was to get a wide scope of the literature with breadth and depth. Previous reviews have often rated the quality of studies so the present review, which updates previous reviews but whose aim is to consider the gender perspectives, did not entail the appraisal and exclusion of articles based on the quality of research methodology [17].

\section{Participant criteria}

Trials were included if they specified an inclusion criterion of 60 years of age or over. Trials that include younger participants were included if the mean age minus one standard deviation was more than 60 years. Participants could be community dwelling or living in residential settings but not if they were currently in hospital settings. 


\section{Inclusion criteria}

- majority of participants being aged $\geq 60$ years (see above)

- living in the community or in care home settings, with any medical condition[s]

- presented the views and preferences on fall prevention exercise programs by the older people

\section{Exclusion criteria}

- studies not reporting views on exercise to prevent falls

- studies not specific to fall prevention

- studies which only reported adherence to a program or program components, not reasons for non-adherence

- studies limited to perspectives of significant others or personnel

- patients within a hospital ward setting

- studies not presented in English

\section{Literature search}

The electronic databases PubMed, CINAHL, Amed, PsycINFO, Scopus, PEDro, and OTseeker were searched for applicable studies, up to February 2016. A professional librarian was consulted to plan the search strategy. The search terms were free-text and 'medical subject heading' $(\mathrm{MeSH})$ terms combined with appropriate Boolean operators. An additional file explains the search strategy in more detail (see Additional file 1). Limits were set to peer reviewed articles written in English, concerning human subjects. In addition the reference lists of all included papers and identified reviews $[13,14,18,19]$ were screened for further articles.

\section{Study selection process and data extraction}

Search returned titles were reviewed for inclusion by two authors (MS/LLO). In all cases of uncertainty the abstract or the full text article was read. Discrepancies were discussed and resolved between the two reviewers, where necessary, involving one of the other authors. Data extraction and analysis of the included articles was performed by two pairs of authors (all authors read a selection of articles) independently. Data was extracted into tables summarizing: aim; methods; number and characteristics of participants; participant's views and preferences on fall prevention exercise programs. Notes were made on any gender perspectives found or reported. Profession and gender of the authors was extracted by the first author. The final data extraction tables were checked by all authors. Studies were not ranked on quality.

\section{Data synthesis}

Since studies of all designs were included, the standard systematic review steps for mixed studies reviews with a convergent qualitative design was used to synthesize the results [20]. The views and preferences reported in the articles were coded and categorized by the first author into facilitators and barriers to falls prevention exercise. Within these two categories the codes were analyzed and summarized into themes using a thematic analysis approach [21]. The first author made the first analysis into themes and these were later presented and discussed within the author group until consensus was reached. In addition, all quotes related to gender differences in the participant's views and preferences were identified. However, due to potential bias in the selection of quotes made by the original studies authors, and a limited number of quotes found, no formal analyses of these quotes was performed.

\section{Results}

\section{Characteristics of the included studies}

The literature search and inclusion of articles are presented, as recommended, following the PRISMA guidelines [22]. A total of 1476 articles were identified in the search. After removing duplicates, 909 abstracts were screened, 56 met the inclusion criteria. After full text screening, 25 of the retrieved papers were considered appropriate to include in this review based on the inclusion and exclusion criteria [23-47] (Fig. 1).

The aim, study design, and number of participants of the included studies are presented in Tables 1 (quantitative and mixed) and 2 (qualitative). Over half of the 25 studies identified for inclusion were conducted within the last six years (2010 or later). Most of these studies originated in Europe $(n=14)$, some in Australia or New Zealand $(n=7)$, and Asia $(n=3)$ and one in the USA. Most studies were set in the community, only one study included nursing-home residents. Fifteen studies included participants who had actually started some form of fall prevention exercises while nine studies did not encompass an actual intervention but investigated older adults' intention to undertake fall prevention interventions, including exercise. One study included people with experiences of participation and non-participation. The type of exercises involved in the studies were group based $(n=6)$, home based $(n=4)$ and a mix of both home and group exercises $(n=5)$. The exercise programs generally included both strength and balance components, including The Otago Exercise Programme [48] and Falls Management Exercise - FaME [49], one study investigated Tai Chi [29] and one study aqua-aerobics [35].

The most common data collection method used to explore participant's views and preferences of fall prevention exercises was one to one interviews $(n=13)$ followed by focus group discussions $(n=10)$ and surveys $(n=4)$. Several studies used a mix of qualitative 


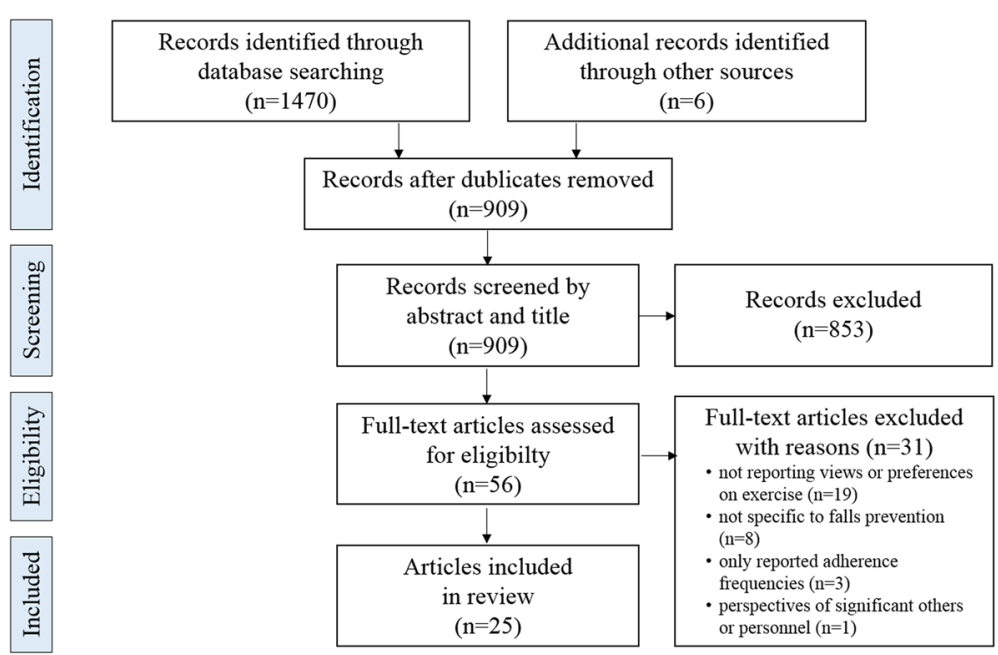

Fig. 1 Details on the process of including papers for this mixed studies review

methods. Mixed methods with both qualitative and quantitative design was used in two studies.

The number of participants in all included studies was about 7000 . About $90 \%$ of the participants were included in studies involving postal surveys. All studies, except two [32, 47], had a minimum age of 60 years for inclusion and, based on available information, the mean age of all participants was approximately 76 years. Three of the studies did not report the gender distribution of the sample $[24,30,39]$ but in the remaining studies the mean proportion of included women was $76 \%$.

Not only were participants primarily female, but the authors were as well. The first author was a female in $88 \%$ of the studies and the mean proportion of male authors was $20 \%$. This may be a reflection of the disciplines of the authors. The first author was a physiotherapist in $40 \%$ and a nurse in $28 \%$ of the studies each. The remaining studies were authored either by medical doctors, health psychologists, occupational therapists or other experts in public health.

\section{Gendered views of older adults to falls prevention exercise}

Only five of the 25 articles retrieved in this review included some sort of gender analysis, regarding similarities or differences in men's and women's perceptions on fall prevention exercises [24, 30, 43, 46, 47]. None of these studies included participants already taking part in exercise to prevent falls. Two of these gender analyses were based on surveys, two on focus group discussions and one on interviews. In the articles without an explicit gender analysis $(n=20)$ the sex of the quoted participants was reported in $56 \%$ of the qualitative papers. Four studies included women only.

Results from the limited gender analysis performed indicate that men protectively identify women as high- priority recipients of balance and fall prevention exercise and that women see themselves as more receptive to fall prevention messages than men [24]. In addition the results indicate that men rely on women for motivation to enroll in health programs [24]. Even though many women seem to consider themselves as already active enough in their everyday life [30,43], significantly more women than men are likely to attend group sessions [47]. However, the results seem inconclusive as to whether women are more or less inclined than men to undertake strength and balance training specifically $[46,47]$ (Table 1). No studies contained information on women and men's specific preferences for program characteristics (e.g. approach) in exercise to prevent falls. See summary in Tables 1 and 2.

\section{Older participants views and preferences on fall prevention exercise}

Facilitators and barriers for taking part in fall prevention exercises, expressed by older women and men as a group, from the 25 included studies, are reported in Table 3 . The three most commonly occurring themes emerging as facilitators for commencement or adherence to an exercise program were: support from professionals or family; social interaction; and perceived benefits. In addition to these frequently represented themes, three other themes emerged: a supportive exercise context; feelings of commitment; and having fun. Being recommended or invited to join fall prevention exercise by a professional or having a professional instructor giving individually tailored exercises were repeatedly reported as important for improving uptake and adherence, as was social support and approval from family and friends. Social interaction was a recurrent theme in the studies as an important factor of relevance for adherence, it could sometimes even be a goal in 


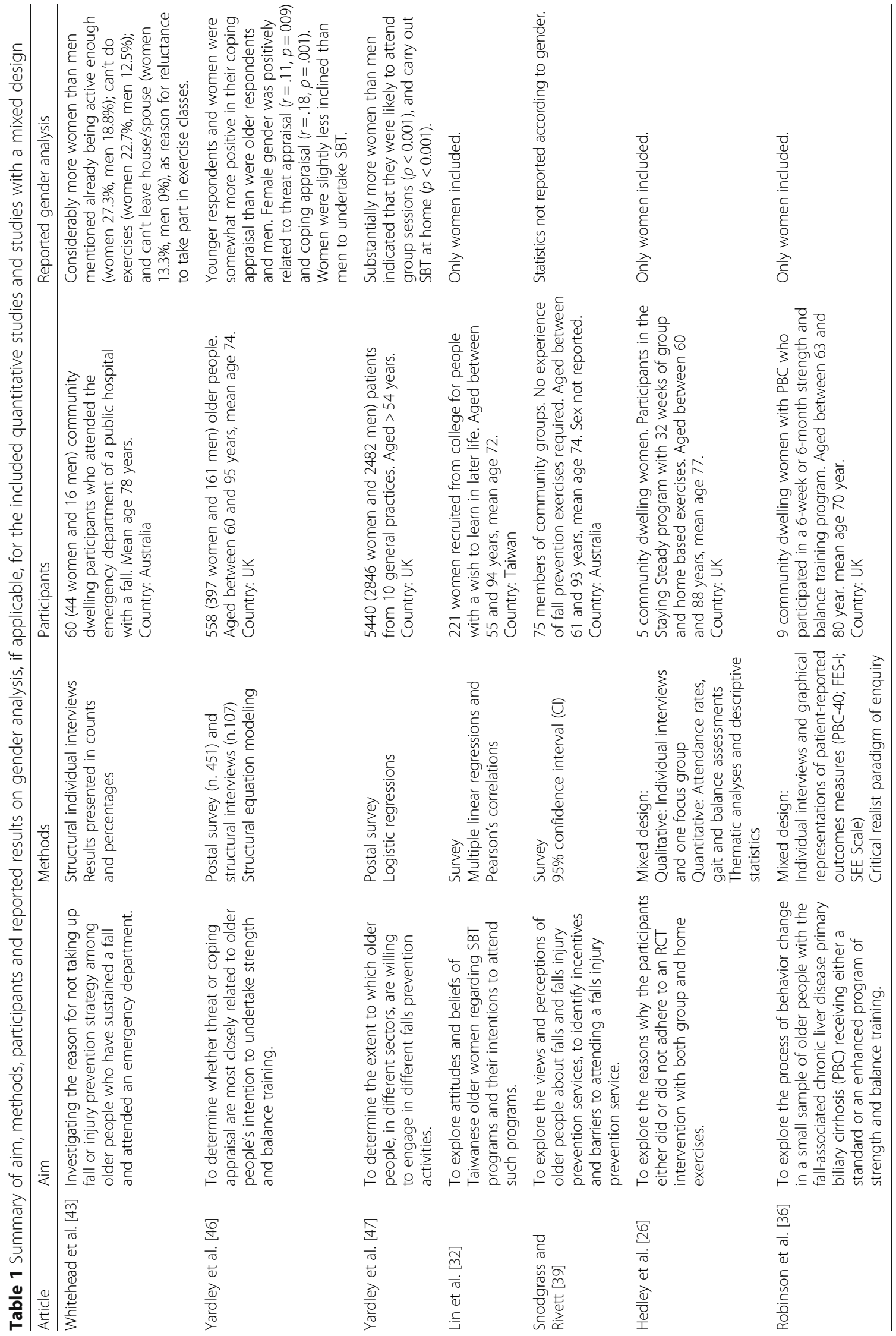




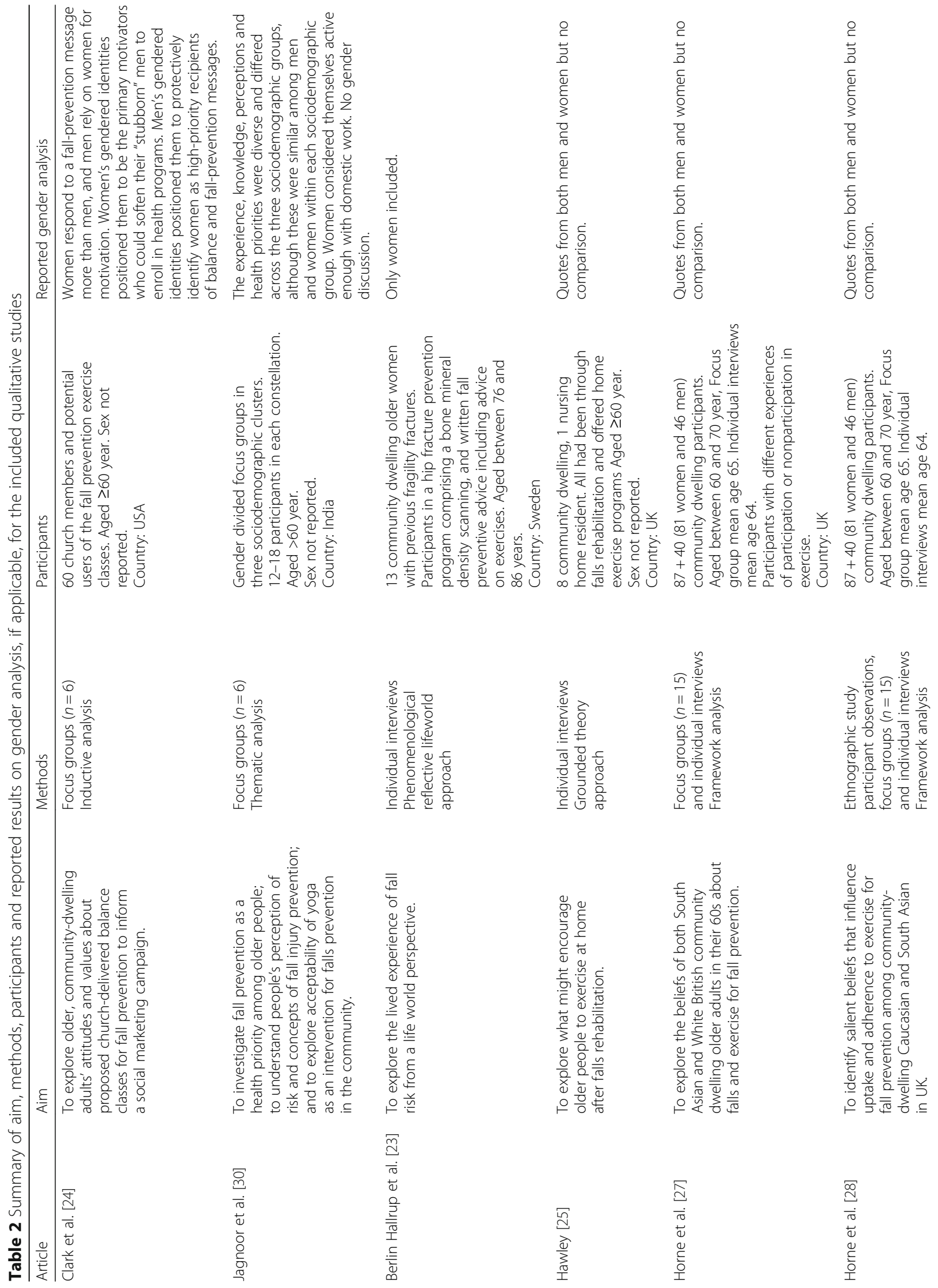




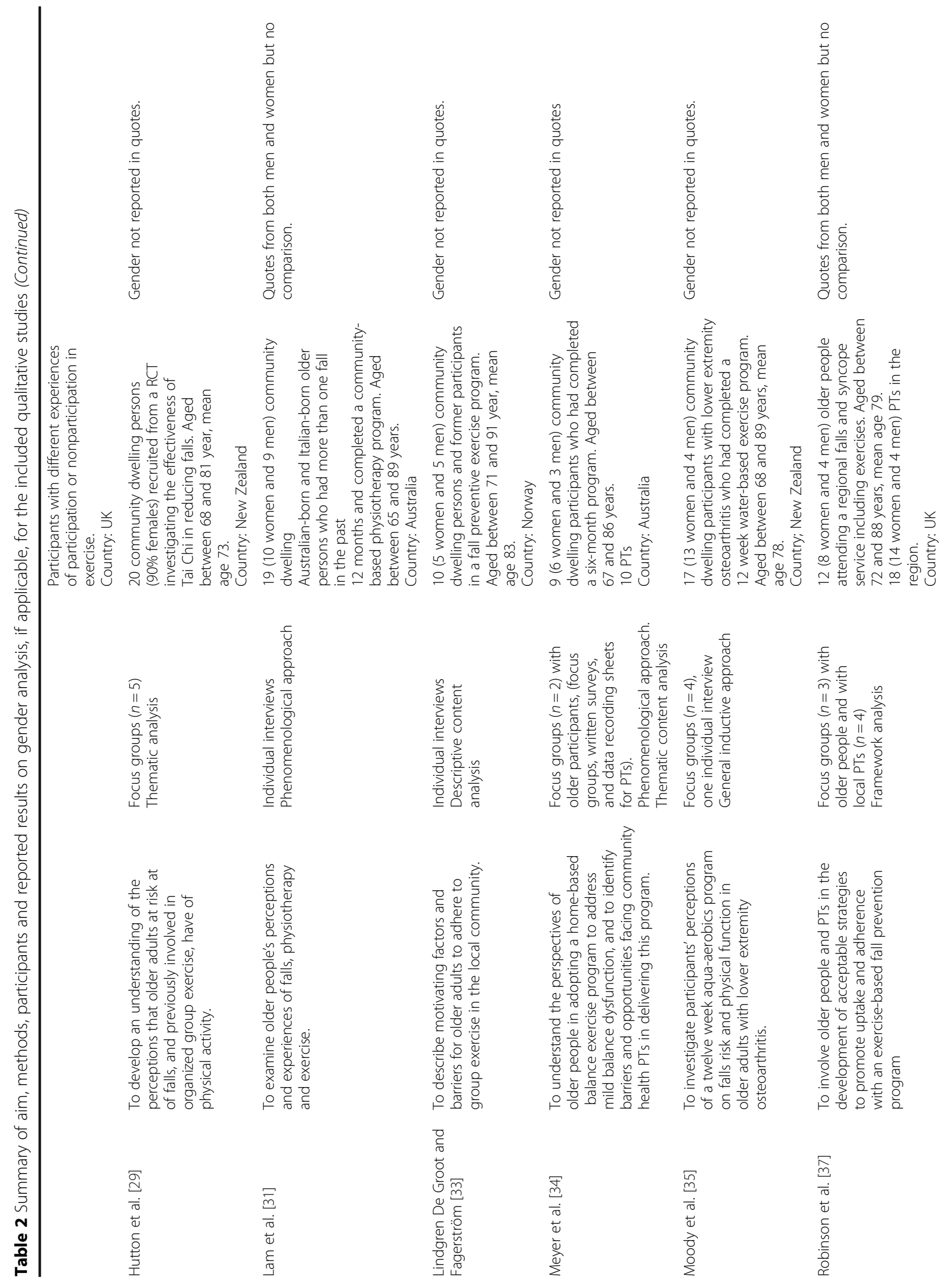




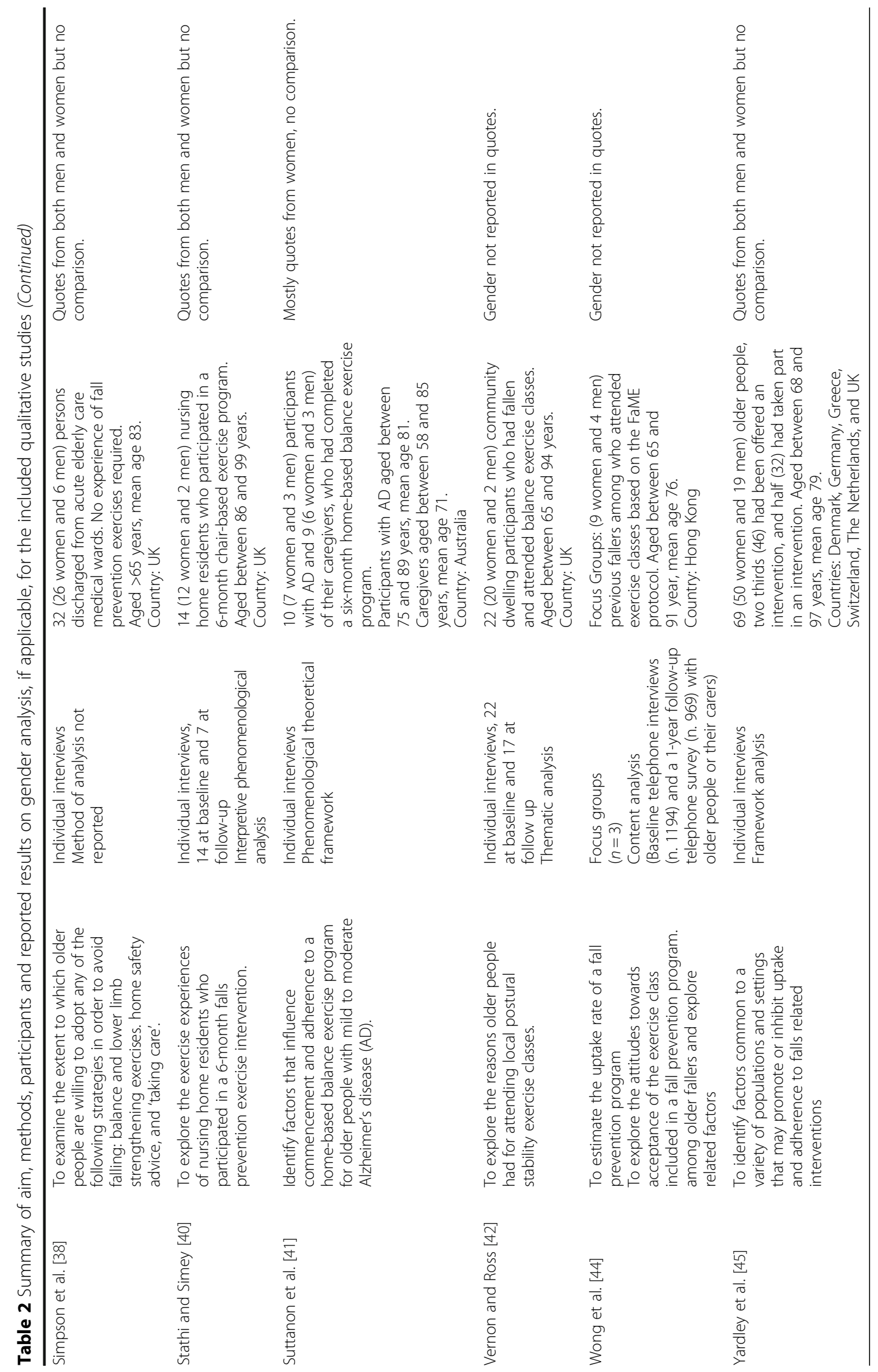




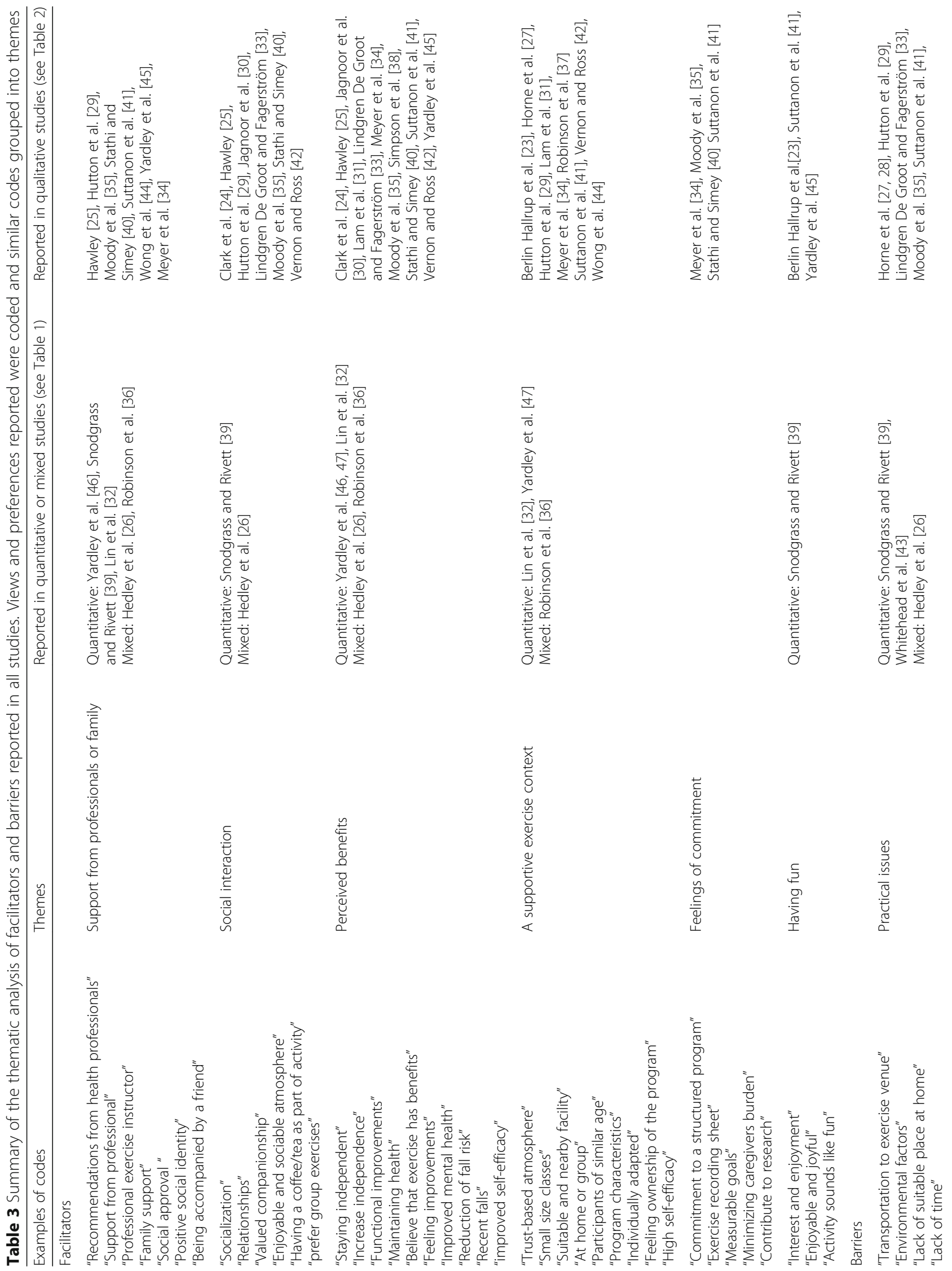


Sandlund et al. BMC Geriatrics (2017) 17:58

Page 10 of 14

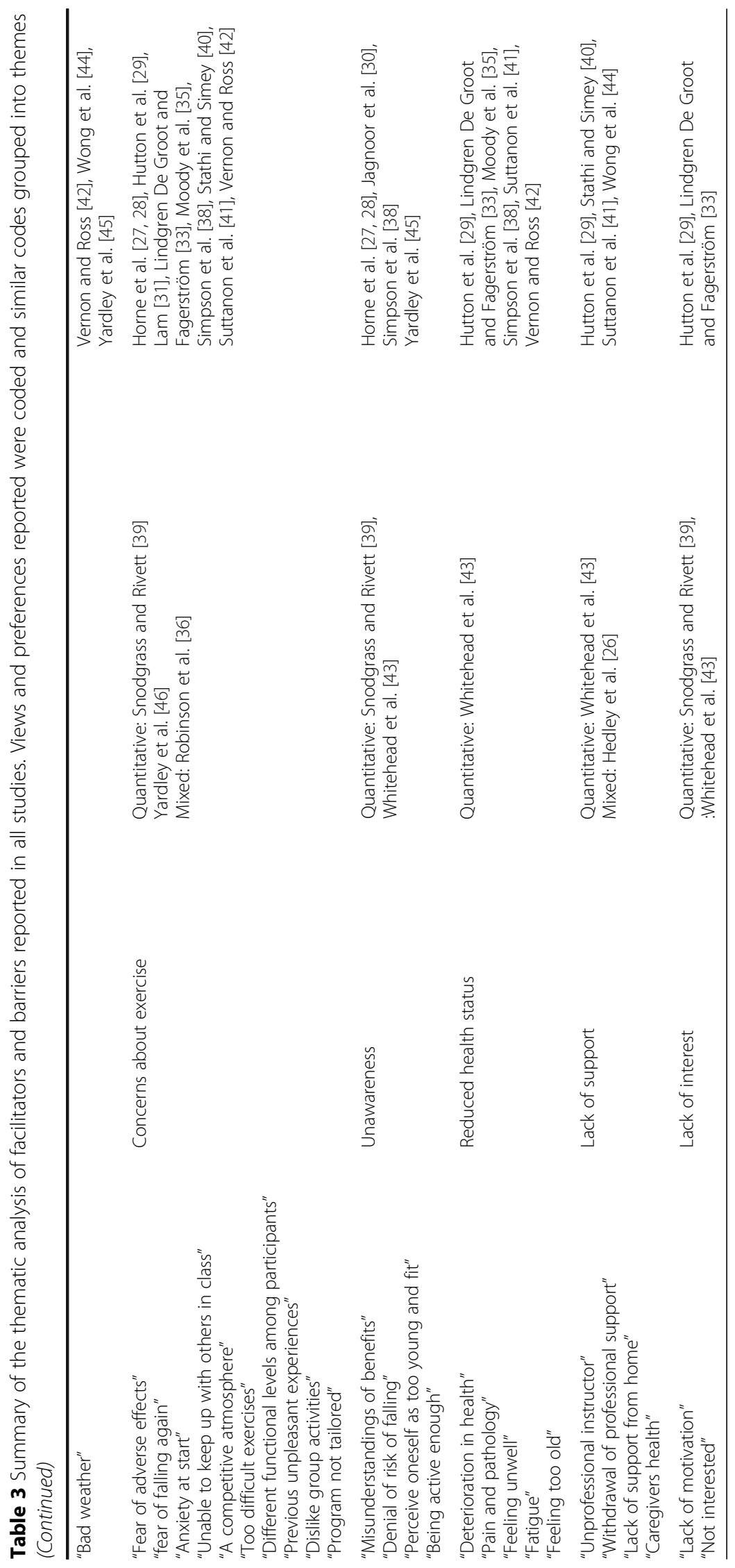


itself and thereby important for uptake as well. Another theme frequently occurring in the studies was the importance of perceived benefits, meaning that the exercises were recognized as beneficial for improving or maintaining personal health and in particular for staying independent. The importance of a supportive exercise context was found in several studies, and included aspects such as an atmosphere of trust, small classes and easy access to exercise venues. Feelings of commitment was another recurrent theme reflecting the participants' willingness to pursue a program (adherence) and to do it well, but also to contribute, for example by reducing a caregivers burden or contribute to research. The last theme, having fun, emphasizes the importance of enjoyment and playfulness as incentives for both uptake and adherence.

The barriers for taking part in fall prevention exercise were expressed in six themes: practical issues; concerns about exercise; unawareness; reduced health status; lack of support; and lack of interest. Practical issues were mentioned in the majority of the studies as the reason for not taking part in exercises. Such barriers were often related to transportation to exercise venues, but could also be lack of time, bad weather, or lack of a suitable place to exercise at home. Another barrier that was highlighted in many studies was the concerns older people had about the exercise. Many older people voiced a lack of confidence to do exercises and fear of adverse effects or a new fall. Concerns about not being able to 'keep up' with demanding exercises, or what other participants could manage, were also expressed. At the same time, for those who were functionally able, groups composed of participants at lower functional levels could also be frustrating. Unpleasant experiences from previous exercise or dislike of group exercises with a competitive atmosphere could also pose a barrier for taking part. Unawareness was another barrier and included lack of knowledge about specific benefits of exercise for fall prevention, older people perceiving they were already active enough, and denial of fall risk. Reduced health, such as pain, fatigue or other illness, as well as lack of support in their situation was another barrier. Some older people simply expressed that they were not interested in fall prevention exercises.

It was not possible to determine whether older adults preferred group or home based exercises as studies rarely offer both approaches. It seemed that the type of intervention included in the particular studies affected the participants' preferences, so that they preferred what they had been offered. The results of the few studies offering both alternatives suggest that home exercises are more difficult to adhere to than the group sessions [26] and that older people rely on their own judgment when deciding on whether to take part in group or individual exercise, based on their exercise abilities, transportation issues, and willingness to expose their disabilities to others [23].

\section{Discussion}

The main aim of this review was to explore any gender differences in views about or preferences for falls prevention exercise within the current literature. Unfortunately, only five of the articles in this review included a gender analysis of similarities or differences in men's and women's perceptions on fall prevention exercises, and none of these investigated if specific approaches attracted women or men differently. Despite the difficulties in making conclusions due to the differing designs and small number of studies, in terms of 'views', the results suggest that women are seen as high-priority recipients of balance and fall prevention messages by both women and men. Though incidentally, perhaps researchers also view women as high-priority participants as the mean proportion of included women in the studies was $76 \%$. Women seem more receptive to fall prevention messages compared to men and are more likely to attend group sessions. No studies considered preferences of men and women and whether these differed or would affect uptake or adherence.

If services want to attract both older women and men to fall prevention exercise they need to consider how these programs are marketed and designed, taking into account the preferences of older men and women. A large consumer market research study based on numerous focus group discussions, individual interviews and surveys concluded that messages must move beyond transmission of basic health information and focus on encouragement and inspiration, while being careful not to alienate [50]. Messages will have more meaning if they are informed by knowledge on potential gender specific preferences.

With respect to the gender, according to this review it seems as if men are often not considered as being in need of fall prevention, both by themselves and society in general. These results conform to recent research showing that men to a lesser degree report and discuss falls and fall prevention with a healthcare provider [15]. One large survey to gain insight into the barriers to recruiting and engaging older men in evidence-based health promotion programs found that $78 \%$ of the respondents agreed that the perception of exercise programs as feminine was a barrier and over $90 \%$ of the survey respondents believed program advertisements featuring men would increase their participation [51].

The reason for this pattern can be discussed in relation to constructions of masculinity and gendered identities. From this perspective, gender does not reside in the person but is viewed as a dynamic, social structure in which men and women conforms to stereotypic beliefs and behaviors based on dominant norms of femininity 
and masculinity. According to the norms, men should be independent, self-reliant, strong, tough and willing to take risks [52]. In addition, this view of masculinity includes denial of weakness or vulnerability and rejection of feminine ideals, which include positive health beliefs or behaviors. These gendered identities are believed to foster both unhealthy behavior among men and undermine men's attempts to adopt healthier habits [53]. It is important to know if men are less likely to take up falls prevention exercise as this could be considered as them being frail and needing help to maintain independence. For example, one study gave a quote from a Greek man "You should be very careful about the way you would approach old men and tell them that they might need to participate in this... Not everybody accepts his age and his state" [45]. Would joining a group program of exercise with women be a threat to their identity? These are questions we cannot answer with the current literature. Of course, it is also possible that exercise preferences for older men and women with a history of falls may not differ, as is the case with men and women with multiple sclerosis [54]. However, with the much smaller number of men included in studies on exercise to prevent falls we cannot be sure that part of the reason is the lack of identification with such programs by men.

A clear trend when investigating participant's preferences for fall prevention exercise, was that women do research on and for women. If researchers or clinicians tend to favor the inclusion of women in prevention programs, gender bias (conscious or unconscious) may arise and stereotype gendered views and identities may be confirmed [55]. Researchers and clinicians need to be aware of their own gendered identities and how they are influenced by gender relations [56] in order not to strengthen or reinforce stereotypical gender views.

This review has, from 25 included studies, identified six themes as facilitators and six themes as barriers for older people either starting or adhering to fall prevention exercise, irrespective of gender (Table 3). The identified facilitators and barriers concur well with the results of previous (non-gender specific) reviews, which included perceptions of fall prevention interventions including exercise $[13,14]$. Recurrent themes were the need for social and professional support and that exercise is perceived as beneficial and important for maintaining independence. Barriers related to practical issues, like access to programs and lack of support, were consistent [14] as were perceived poor health, poor self-efficacy, fear of falling, underestimation of fall risk and concerns about exercise [13].

The psychosocial factors expressed by the older participants as important for engagement in fall prevention exercises conforms well with many health psychology theories commonly used to predict health behaviors, in particular the theory of planned behavior (TPB) [57]. This theory has previously been applied in fall prevention research [58] and was also used in four of the included studies [27, 32, 45, 46]. From the 25 studies in this review it is apparent that older people's attitudes to the effects of exercises are mainly positive. Older people are often aware of the beneficial effects of physical exercise to improve their general health, and this knowledge motivates them to be active. However, exercise performed merely with the goal to prevent future falls, does not seem enough to attract this population. This attitude has previously been explained by two coupled factors: (a) a belief that falls cannot be prevented, but are caused by external circumstances and bad luck, and (b) an underestimation of the personal perceived fall risk [58]. The influence of a subjective norm was confirmed as essential for many older people's commencement or adherence to an exercise program. Both professional and social support as well as social interaction during fall prevention exercise was commonly reported as important factors in the studies reviewed. Many of the barriers reported related to a perceived lack of control over the exercise situation, such as practical issues and various concerns about the exercises including lack of confidence, worries about not being able to keep up with others, and fear of adverse effects.

A number of methodological features could influence the result of this review. A strength is the broad literature search in a number of electronic databases, done systematically with the consultation of a librarian. However, despite the efforts to identify all eligible publications, we cannot exclude the possibility that some were missed. The lack of generally used keywords for participant's views and preferences and the diverse research methodologies used in the studies aiming for made it difficult to develop a comprehensive search strategy. In order to compensate for this difficulty, the reference lists of all included articles and previous resembling reviews were searched for additional publications, which resulted in a few more studies to include. No ranking of quality of the included studies was performed.

\section{Conclusion}

In conclusion, although there is plenty of information on the facilitators and barriers to falls prevention exercise in older people, there is a distinct lack of studies investigating differences or similarities in older womens' and mens' views regarding fall prevention exercise. In order to ensure that fall prevention exercise is appealing to both sexes and that the inclusion of both men and women are encouraged, more research is needed on preferences to find out whether any gender differences exists and whether and how practitioners need to offer a range of opportunities and support strategies to attract both women and men to falls prevention exercise. 


\section{Additional file}

Additional file 1: Literature search. (PDF $152 \mathrm{~kb}$ )

\section{Acknowledgements}

Our thanks to Umeå University library for valuable advice when planning the literature search

\section{Funding}

This work has been funded by: The Swedish Research Council, Dnr 2015-03481; The Strategic Research Programme in Care Sciences, Umeå University and The Karolinska Institute, Sweden, and a grant provided by Umeå University for DS as a visiting Professor

\section{Availability of data and materials}

The data supporting the conclusions of this article are included within the article and its additional file. Detailed information on the database search is provided in the Additional file 1. Figure 1 shows a flowchart of the literature search, exclusion and inclusion of articles, further information on the excluded studies will be provided by the authors on request. Tables 1 and 2 summarize the aim, methods, participants and gender analysis, if applicable, of the included studies. Table 3 summarize the thematic analysis of facilitators and barriers reported in all studies.

\section{Authors' contributions}

MS carried out the systematic search with help of the consulted librarian, selected the studies for inclusion, extracted data and summarized included studies, performed the qualitative coding and synthesized codes into themes, revised the themes following discussions and negotiations with all co-authors, and wrote the manuscript. DAS contributed to extract data and summarize the included studies, discussed and negotiated the themes, revised the tables, and revised and commented on the manuscript. PP contributed to extract data and summarize the included studies, discussed and negotiated the themes, and revised and commented on the manuscript. CA contributed to extract data and summarize the included studies, discussed and negotiated the themes, wrote paragraphs in the discussion, and revised and commented on the manuscript. AMW contributed to extract data and summarize the included studies, discussed and negotiated the themes, and revised and commented on the manuscript. LLO selected the studies for inclusion, contributed to extract data and summarize the included studies, discussed and negotiated the themes, and revised and commented on the manuscript. MS is the guarantor. All authors read and approved the final manuscript.

\section{Competing interests}

The authors declare that they have no competing interests.

\section{Consent for publication}

Not applicable.

\section{Ethics approval and consent to participate}

Not applicable.

\section{Author details}

${ }^{1}$ Department of Community Medicine and Rehabilitation, Physiotherapy, Umeå University, Umeå, Sweden. ${ }^{2}$ School of Health and Life Sciences, Glasgow Caledonian University, Glasgow, UK. ${ }^{3}$ Department of Rehabilitation and Department of Medical and Health Sciences, Linköping University, Linköping, Sweden. ${ }^{4}$ Department of Health Sciences, Division of Health and Rehabilitation, Luleå University of Technology, Luleå, Sweden.

Received: 22 June 2016 Accepted: 14 February 2017

Published online: 17 February 2017

\section{References}

1. Campbell AJ, Borrie MJ, Spears GF. Risk factors for falls in a community-based prospective study of people 70 years and older. J Gerontol. 1989;44:M112-7.

2. Stevens JA Corso PS, Finkelstein EA, Miller TR. The costs of fatal and non-fatal falls among older adults. Inj Prev. 2006;12:290-5.
3. Nordstrom P, Eklund F, Bjornstig U, Nordstrom A, Lorentzon R, Sievanen $H$, Gustafson Y. Do both areal BMD and injurious falls explain the higher incidence of fractures in women than in men? Calcif Tissue Int. 2011;89:203-10.

4. Stevens JA, Ryan G, Kresnow M. Fatalities and injuries from falls among older adults United States, 1993-2003 and 2001-2005. JAMA. 2007;297:32-3.

5. Pereira $\mathrm{CL}$, Baptista F, Infante P. Men older than 50 year are more likely to fall than women under similar conditions of health, body composition, and balance. Am J Phys Med Rehabil. 2013;92:1095-103.

6. Gillespie LD, Robertson MC, Gillespie WJ, Sherrington C, Gates S, Clemson LM, Lamb SE. Interventions for preventing falls in older people living in the community. Cochrane Database Syst Rev. 2012;9:CD007146.

7. Sherrington C, Tiedemann A, Fairhall N, Close JC, Lord SR. Exercise to prevent falls in older adults: an updated meta-analysis and best practice recommendations. N S W Public Health Bull. 2011;22:78-83.

8. Davis JC, Robertson MC, Ashe MC, Liu-Ambrose T, Khan KM, Marra CA. Does a home-based strength and balance programme in people aged $>$ or $=80$ years provide the best value for money to prevent falls? A systematic review of economic evaluations of falls prevention interventions. Br J Sports Med. 2010:44:80-9.

9. El-Khoury F, Cassou B, Charles MA, Dargent-Molina P. The effect of fall prevention exercise programmes on fall induced injuries in community dwelling older adults: systematic review and meta-analysis of randomised controlled trials. BMJ. 2013;347:f6234.

10. Nyman SR, Victor CR. Older people's participation in and engagement with falls prevention interventions in community settings: an augment to the Cochrane systematic review. Age Ageing. 2012;41:16-23.

11. McPhate L, Simek EM, Haines TP. Program-related factors are associated with adherence to group exercise interventions for the prevention of falls: a systematic review. J Physiother. 2013;59:81-92.

12. Clemson L, Fiatarone Singh MA, Bundy A, Cumming RG, Manollaras K, $\mathrm{O}^{\prime}$ Loughlin P, Black D. Integration of balance and strength training into daily life activity to reduce rate of falls in older people (the LiFE study): randomised parallel trial. BMJ. 2012;345:e4547

13. Bunn F, Dickinson A, Barnettpage E, McInnes E, Horton K. A systematic review of older people's perceptions of facilitators and barriers toparticipation in fallsprevention interventions. Ageing Soc. 2008;28:449-72.

14. McMahon S, Talley KM, Wyman JF. Older people's perspectives on fall risk and fall prevention programs: a literature review. Int J Older People Nurs. 2011;6:289-98

15. Stevens JA, Ballesteros MF, Mack KA, Rudd RA, DeCaro E, Adler G. Gender differences in seeking care for falls in the aged Medicare population. Am J Prev Med. 2012;43:59-62.

16. Ransdell LB, Vener JM, Sell K. International perspectives: the influence of gender on lifetime physical activity participation. J R Soc Promot Health 2004:124:12-4

17. Khalil H, Peters M, Godfrey CM, Mclnerney P, Soares CB, Parker D. An evidencebased approach to scoping reviews. Worldviews Evid Based Nurs. 2016;13:118-23.

18. Hawley-Hague H, Boulton E, Hall A, Pfeiffer K, Todd C. Older adults' perceptions of technologies aimed at falls prevention, detection or monitoring: a systematic review. Int J Med Inform. 2014;83:416-26.

19. Jang $H$, Clemson L, Lovarini M, Willis K, Lord SR, Sherrington C: Cultural influences on exercise participation and fall prevention: a systematic review and narrative synthesis. Disabil Rehabil. 2015:2:1-9.

20. Pluye P, Hong QN. Combining the power of stories and the power of numbers: mixed methods research and mixed studies reviews. Annu Rev Public Health. 2014;35:29-45.

21. Braun V, Clarke V. Using thematic analysis in psychology. Qual Res Psychol. 2006;3:77-101.

22. Liberati A, Altman DG, Tetzlaff J, Mulrow C, Gotzsche PC, loannidis JPA, Clarke M, Devereaux PJ, Kleijnen J, Moher D. The PRISMA statement for reporting systematic reviews and meta-analyses of studies that evaluate health care interventions: explanation and elaboration. PLoS Med. 2009;6:7.

23. Berlin Hallrup L, Albertsson D, Bengtsson Tops A, Dahlberg K, Grahn B. Elderly women's experiences of living with fall risk in a fragile body: a reflective lifeworld approach. Health Soc Care Community. 2009;17:379-87.

24. Clark L, Thoreson S, Goss CW, Zimmer LM, Marosits M, Diguiseppi C. Understanding fall meaning and context in marketing balance classes to older adults. J App Gerontol. 2013:32:96-119.

25. Hawley H. Older adults? perspectives on home exercise after falls rehabilitation: Understanding the importance of promoting healthy, active ageing. Health Educ J. 2009;68:207-18. 
26. Hedley L, Suckley N, Robinson L, Dawson P. Staying steady: a communitybased exercise initiative for falls prevention. Physiother Theory Pract. 2010; 26:425-38

27. Horne M, Skelton DA, Speed S, Todd C. Falls prevention and the value of exercise: salient beliefs among south asian and white british older adults. Clin Nurs Res. 2014;23:94-110.

28. Horne M, Speed S, Skelton D, Todd C. What do community-dwelling Caucasian and South Asian 60-70 year olds think about exercise for fall prevention? Age Ageing. 2009;38:68-73.

29. Hutton L, Frame R, Maggo H, Shirakawa H, Mulligan H, Waters D, Hale L. The perceptions of physical activity in an elderly population at risk of falling: a focus group study. NZ J Physiother. 2009;37:85-92.

30. Jagnoor J, Keay L, Jaswal N, Kaur M, Ivers R. A qualitative study on the perceptions of preventing falls as a health priority among older people in Northern India. Inj Prev. 2014;20:29-34.

31. Lam J, Liamputtong P, Hill K. Falls, falls prevention and the role of physiotherapy and exercise: perceptions and interpretations of Italian-born and Australian-born older persons living in Australia. J Cross Cult Gerontol. 2015;30:233-49.

32. Lin S-F, Lee JW, Modeste N, Johnson EG. Attitudes and beliefs predicting Taiwanese older adults' intentions to attend strength and balance training programs. J Appl Gerontol. 2012;31:260-81.

33. Lindgren De Groot GC, Fagerström L. Older adults' motivating factors and barriers to exercise to prevent falls. Scand J Occup Ther. 2011;18:153-60.

34. Meyer C, Williams S, Batchelor F, Hill K. Enhancing adoption of a homebased exercise program for mild balance dysfunction: a qualitative study. J Aging Phys Activ. 2016;24:53-60.

35. Moody J, Hale L, Waters D. Perceptions of a water-based exercise programme to improve physical function and falls risk in older adults with lower extremity osteoarthritis: barriers, motivators and sustainability. NZ J Physiother. 2012;40:64.

36. Robinson L, Newton JL, Jones D, Dawson P. Promoting self-management and adherence with strength and balance training for older people with long-term conditions: a mixed-methods study. J Eval Clin Pract. 2014;20:318-26.

37. Robinson L, Newton $J$, Jones D, Dawson P. Self-management and adherence with exercise-based falls prevention programmes: a qualitative study to explore the views and experiences of older people and physiotherapists. Disabil Rehabil. 2014;36:379-86.

38. Simpson JM, Darwin C, Marsh N. What are older people prepared to do to avoid falling? A qualitative study in London. Br J Community Nurs. 2003; 8(152):154-9.

39. Snodgrass SJ, Rivett DA. Perceptions of older people about falls injury prevention and physical activity. Australas J Ageing. 2005;24:114-8.

40. Stathi A, Simey P. Quality of life in the Fourth Age: exercise experiences of nursing home residents. J Aging Phys Act. 2007;15:272-86.

41. Suttanon P, Hill KD, Said CM, Byrne KN, Dodd KJ. Factors influencing commencement and adherence to a home-based balance exercise program for reducing risk of falls: perceptions of people with Alzheimer's disease and their caregivers. Int Psychogeriatr. 2012;24:1172-82.

42. Vernon S, Ross F. Participation in community exercise classes: barriers to access. Br J Community Nurs. 2008;13:89-92.

43. Whitehead $\mathrm{CH}$, Wundke $\mathrm{R}$, Crotty $\mathrm{M}$. Attitudes to falls and injury prevention: what are the barriers to implementing falls prevention strategies? Clin Rehabil. 2006;20:536-42.

44. Wong EL, Woo J, Cheung AW, Yeung PY. Determinants of participation in a fall assessment and prevention programme among elderly fallers in Hong Kong: prospective cohort study. J Adv Nurs. 2011;67:763-73.

45. Yardley L, Bishop FL, Beyer N, Hauer K, Kempen Gl, Piot-Ziegler C, Todd CJ, Cuttelod T, Horne M, Lanta K, et al. Older people's views of falls-prevention interventions in six European countries. Gerontologist. 2006;46:650-60.

46. Yardley L, Donovan-Hall M, Francis K, Todd C. Attitudes and beliefs that predict older people's intention to undertake strength and balance training. J Gerontol B Psychol Sci Soc Sci. 2007;62:P119-25.

47. Yardley L, Kirby S, Ben-Shlomo Y, Gilbert R, Whitehead S, Todd C. How likely are older people to take up different falls prevention activities? Prev Med. 2008:47:554-8.

48. Robertson MC, Devlin N, Scuffham P, Gardner MM, Buchner DM, Campbell AJ. Economic evaluation of a community based exercise programme to prevent falls. J Epidemiol Community Health. 2001;55:600-6.

49. Skelton D, Dinan S, Campbell M, Rutherford O. Tailored group exercise (Falls Management Exercise - FaME) reduces falls in community-dwelling older frequent fallers (an RCT). Age Ageing. 2005;34:636-9.
50. Ory M, Hoffman MK, Hawkins M, Sanner B, Mockenhaupt R. Challenging aging stereotypes - Strategies for creating a more active society. Am J Prev Med. 2003;25:164-71.

51. Anderson C, Seff LR, Batra A, Bhatt C, Palmer RC: Recruiting and Engaging Older Men in Evidence-Based Health Promotion Programs: Perspectives on Barriers and Strategies. J Aging Res. 2016;2016. ID 8981435.

52. Connell R. Gender, health and theory: conceptualizing the issue, in local and world perspective. Soc Sci Med. 2012;74:1675-83.

53. Courtenay WH. Constructions of masculinity and their influence on men's well-being: a theory of gender and health. Soc Sci Med. 2000;50:1385-401.

54. Asano M, Duquette $P$, Andersen $R$, Lapierre $Y$, Mayo NE. Exercise barriers and preferences among women and men with multiple sclerosis. Disabil Rehabil. 2013;35:353-61.

55. Risberg G, Johansson EE, Hamberg K. A theoretical model for analysing gender bias in medicine. Int J Equity Health. 2009:8:28.

56. Calasanti T. Gender relations and applied research on aging. Gerontologist. 2010;50:720-34.

57. Ajzen I, Fishbein M. Understanding attitudes and prediction social behavior. Englewood Cliffs: Prentice-Hall; 1980.

58. Nyman SR. Psychosocial issues in engaging older people with physical activity interventions for the prevention of falls. Can J Aging. 2011;30:45-55.

\section{Submit your next manuscript to BioMed Central and we will help you at every step:}

- We accept pre-submission inquiries

- Our selector tool helps you to find the most relevant journal

- We provide round the clock customer support

- Convenient online submission

- Thorough peer review

- Inclusion in PubMed and all major indexing services

- Maximum visibility for your research

Submit your manuscript at www.biomedcentral.com/submit
Biomed Central 